\title{
Preliminary Report on Self- Healing Minefield (Frogs) Concepts and Utility in Battle
}

R. J. Greenwalt, D. Magnoli

January 13, 2000

Lawrence

Livermore

National

Laboratory

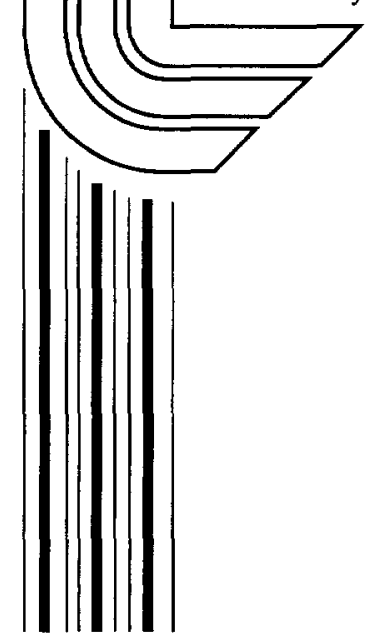




\section{DISCLAIMER}

This document was prepared as an account of work sponsored by an agency of the United States Government. Neither the United States Government nor the University of California nor any of their employees, makes any warranty, express or implied, or assumes any legal liability or responsibility for the accuracy, completeness, or usefulness of any information, apparatus, product, or process disclosed, or represents that its use would not infringe privately owned rights. Reference herein to any specific commercial product, process, or service by trade name, trademark, manufacturer, or otherwise, does not necessarily constitute or imply its endorsement, recommendation, or favoring by the United States Government or the University of California. The views and opinions of authors expressed herein do not necessarily state or reflect those of the United States Government or the University of California, and shall not be used for advertising or product endorsement purposes.

This work was performed under the auspices of the U. S. Department of Energy by the University of California, Lawrence Livermore National Laboratory under Contract No. W-7405-Eng-48.

This report has been reproduced directly from the best available copy.

Available electronically at http://www.doc.gov/bridge

Available for a processing fee to U.S. Department of Energy

And its contractors in paper from

U.S. Department of Energy

Office of Scientific and Technical Information

P.O. Box 62

Oak Ridge, TN 37831-0062

Telephone: (865) 576-8401

Facsimile: (865) 576-5728

E-mail: reports@adonis.osti.gov

Available for the sale to the public from

U.S. Department of Commerce

National Technical Information Service

5285 Port Royal Road

Springfield, VA 22161

Telephone: (800) 553-6847

Facsimile: (703) 605-6900

E-mail: orders@ntis.fedworld.gov

Online ordering: http://www.ntis.gov/ordering.htm

OR

Lawrence Livermore National Laboratory

Technical Information Department's Digital Library

http://www.llnl.gov/tid/Library.html 


\section{Preliminary Report on Self-healing Minefield (Frogs) Concepts and Utility in Battle}

Table of Contents

I. Introduction. ......................................

II. Self-Healing Minefield (Frogs) System Characterization. . . . . . . . . . 2

A. Minefield Ground Pattern. .....................

1. Volcano Minefield Pattern. ................. 3

2. Minefreld Design. ..................... 4

B. Movement Parameters. ......................... 5

1. Technical Analysis. ....................

C. Enemy Breaching. ........................ 10

1. Movement and Breaching Speeds. .............11

2. Breaching. $\ldots \ldots \ldots \ldots \ldots \ldots \ldots \ldots \ldots \ldots \ldots \ldots \ldots \ldots$

3. Basic Breaching Formation. ................ 12

D. Breaching Counters to the Self-Healing Minefield. .......... 13

1. Single Sequential Breach Lane Technique. ......... 13

2. Parallel Breach Technique. ................ 15

3. Wide Lane Breach Technique. ................ 16

E. Breaching Analysis. . . . . . . . . . . . . . . . . 17

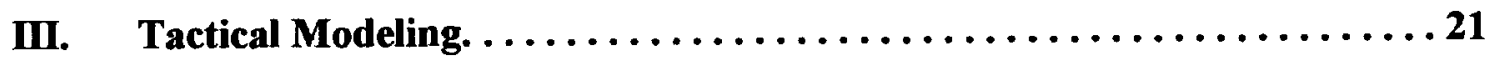

A. The Scenario. ............................. 21

B. The Plans. . . . . . . . . . . . . . . . . . . . . 22

C. Battle Analysis. ......................... 25

D. Preliminary Quantitative Results. ................. 26

1. Duration. ......................... 27

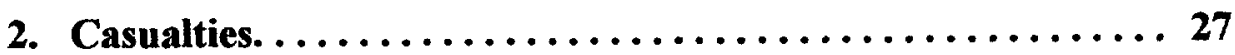


3. Fractional Exchange Ration (FER). . . . . . . . . 29

4. Breaching Costs. ....................... 30

5. Summary. $\ldots \ldots \ldots \ldots \ldots \ldots \ldots \ldots \ldots \ldots \ldots \ldots \ldots \ldots \ldots \ldots \ldots \ldots$

Appendix A. System Characterization Process. .................. A-1 


\section{List of Figures}

Figure 1. Distribution of mines from canister $\ldots \ldots \ldots \ldots \ldots \ldots \ldots \ldots$

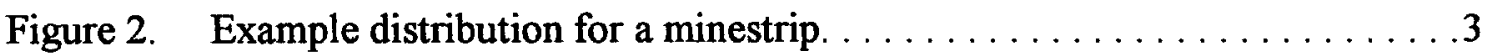

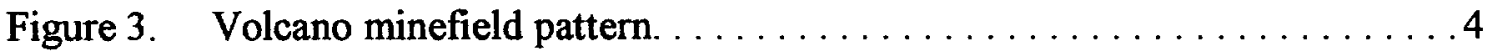

Figure $4 a$. Initial distribution of mines in central strip. $\ldots \ldots \ldots \ldots \ldots \ldots$

Figure $4 b$. Distribution of mines after first breach. $\ldots \ldots \ldots \ldots \ldots \ldots \ldots$

Figure $4 c$. Distribution of mines after first healing. . . . . . . . . . . . 7

Figure $4 \mathrm{~d}$. Distribution of mines after second breach and healing. . . . . . . 8

Figure $4 \mathrm{e}$. Distribution of mines after third breach and healing. . . . . . . . . .9

Figure $4 \mathrm{f}$. Distribution of mines after sixth breach and healing. . . . . . . . . 9

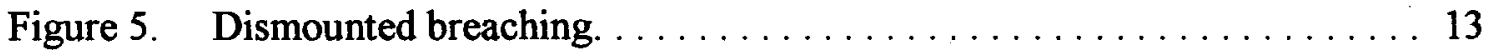

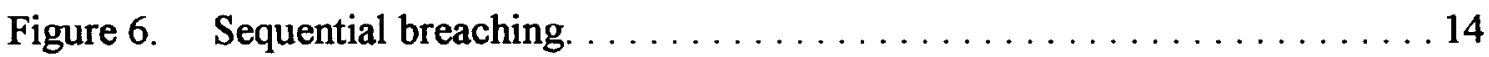

Figure 7. Parallel lanes. . . . . . . . . . . . . . . . . 15

Figure 8. Wide lanes . . . . . . . . . . . . . 16

Figure $9 \mathrm{a}$. Original minefield distribution. $\ldots \ldots \ldots \ldots \ldots \ldots \ldots \ldots \ldots$

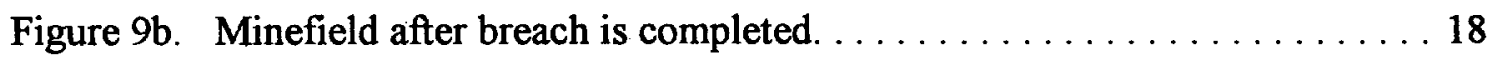

Figure 9c. Minefield distribution after first rearrangement. $\ldots \ldots \ldots \ldots \ldots \ldots$

Figure 9d. Minefield after second breach and healing . . . . . . . . . . . . . . . 19

Figure 9e. Minefield after third breach and healing. . . . . . . . . . . . . . . . 19

Figure 10. Terrain and initial positions of tactical scenario $\ldots \ldots \ldots \ldots \ldots \ldots 22$

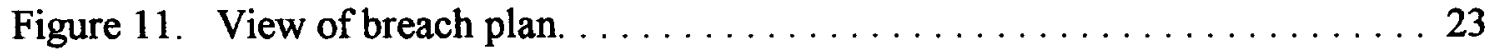

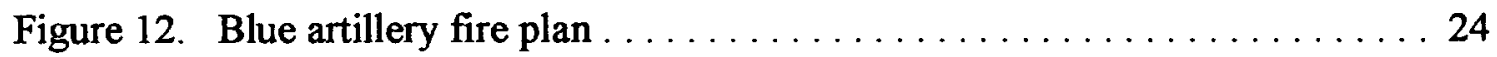

Figure 13. Resulting casualties for Red and Blue $\ldots \ldots \ldots \ldots \ldots$

Figure 14. Total casualties as a fraction of the force $\ldots \ldots \ldots \ldots \ldots \ldots$

Figure 15. Fractional Exchange Ratio . . . . . . . . . . . . . . . . . . . . 29

Figure 16. AT Mines only. . . . . . . . . . . . . 32

Figure 17. Self-healing minefield. . $\ldots \ldots \ldots \ldots \ldots \ldots \ldots \ldots \ldots \ldots \ldots \ldots \ldots \ldots$

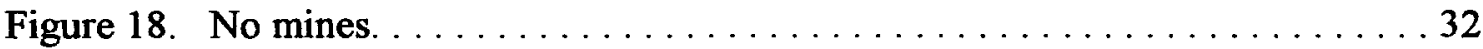

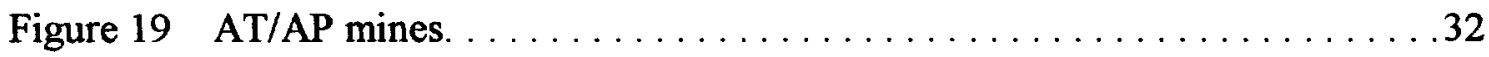




\section{List of Tables}

Table 1. Percent probability that a lane is clear of mines as a function of jump parameters. . . . . . . . . . . . . . . 10

Table 2. Dismounted movement table. . . . . . . . . . . . . . 11

Table 3. Breach analysis results. . . . . . . . . . . . . . 20

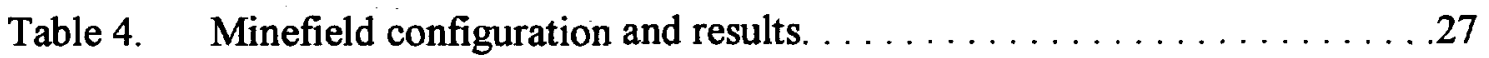

Table 5. Delay multiple. . . . . . . . . . . . . . . 27

Table 6. Red casualty multiple. . . . . . . . . . . . . . . . . . 29

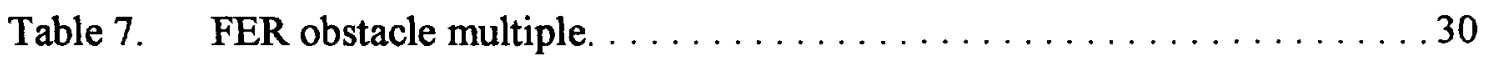

Table 8. Breaching costs. . . . . . . . . . . . 30

Table 9. Required breaching force multiples. . . . . . . . . . . . . 31

Table 10. Breaching force casualties multiples. $\ldots \ldots \ldots \ldots \ldots \ldots \ldots \ldots$

Table 11. Battle times and casualties. . . . . . . . . . . . 32 


\section{Preliminary Report on Self-healing Minefield (Frogs) Concepts and Utility in Battle}

\section{Introduction}

The purpose of this study is to determine battlefield effectiveness of the selfhealing minefield ("Frogs") concept system compared to basecases of the standard AP/AT (anti-personnel / anti-tank) mixed minefield, the AT (anti-tank) pure minefield, and no minefields. This involves tactical modeling where a basecase with and without mines is compared to the concept system. However, it is first necessary to establish system characteristics and behavior of the Frog mine and minefield in order to do the tactical modeling. This initial report provides emerging insights into various minefield parameters in order to allow better program definition early in the conceptual development.

In the following sections of this report, we investigate the self-healing minefield's ground pattern and several concepts for movement ("jump") of a mine. Basic enemy breaching techniques are compared for the different mine movement concepts. These results are then used in the (Joint Conflict and Tactical Simulation) JCATS tactical model to evaluate minefield effects in a combat situation. The three basecases and the Frogs concept are used against a North Korean mechanized rifle battalion and outcomes are compared. Preliminary results indicate:

1. Possible breaching techniques for the self-healing minefield were proposed and compared through simulation modeling. Of these, the best breaching counter to the self-healing minefield is the "wide-lane" breach technique.

2. Several methods for mine movement are tested and the optimal method from this group was selected for use in the modeling. However, continued work is needed on jump criteria; a more sophisticated model may reduce the advantage of the breach counter.

3. The battle scenario used in this study is a very difficult defense for Blue. In the three baseline cases (no mines, AT mines only, and mixed AT/AP minefield), Blue loses. Only in the Frog case does Blue win, and it is a high casualty win.

These results, assumptions used, and direction for further study are discussed in detail in the body of this report. 


\section{Self-healing Minefield (Frogs) System Characterization}

To study battlefield utility of the Frog concept minefield, it was first necessary to develop an understanding of the mine and its interactions within the minefield. This required some initial assumptions on mine parameters, and analysis and selection of values for those parameters, for the simple Frog mine. Identification and quantification of the delivery system's ground pattern are also required.

As the system does not exist except in a relatively sketchy concept, the analyst was free to define necessary technical and operational parameters. The initial distribution of mines on the ground, as well as the movement of the mines, i.e. what makes them jump and how far they move, of both the individual mine and the minefield, were developed by desktop analysis supported by stochastic computer models.

\section{II.A. Minefield ground pattern}

The current family of scatterable mines (FASCAM) includes three primary delivery systems:

- Gator, delivered by high-performance aircraft,

- artillery scatterable mines (RAAM, ADAM, and RADM fired by $155 \mathrm{~mm}$ howitzers), and

- Volcano, carried either by helicopter or by ground vehicle.

The antitank mines in all systems are similar and would be replaced by the Frog. Each system produces a different ground pattern.

Gator is a specialized system designed to be emplaced deep to influence enemy activity at the operational level. It is not normally used in close proximity to friendly forces and consequently was left for later examination.

Artillery scatterable mine systems are used predominantly for situational obstacles. These do not encompass the bulk of the minefields used on the battlefield, and also were left for later analysis.

The Volcano delivery system is the workhorse mine system. It is used to install the bulk of the tactical minefields supporting the battle at the tactical level. Since it is ubiquitous, it was selected as the delivery system for this initial examination of Frog utility. 


\section{II.A.1. Volcano Minefield Pattern}

The Volcano delivery system consists of four identical panels and a controller. The panels are mounted two to a side on a ground vehicle or helicopter and each carries 40 launch canisters. Each canister contains six mines and a small expelling charge. A flexible cable zigzags between the mines and provides an electrical connection to each. It also causes each mine to emerge on a different azimuth and at a different velocity. Figure 1 illustrates this pattern. Azimuths are measured from a perpendicular ejection. Velocities are shown in feet per second. The arrow indicates the direction of helicopter motion.

\section{Mine $1 \quad 3.0^{\circ}$ left $84.5 \mathrm{fps}$ \\ Mine $218.5^{\circ}$ right $72.0 \mathrm{fps}$ \\ Mine $320.0^{\circ}$ left $68.0 \mathrm{fps}$ \\ Mine $427.0^{\circ}$ right $65.0 \mathrm{fps}$ \\ Mine $524.0^{\circ}$ left $61.0 \mathrm{fps}$ \\ Mine $622.0^{\circ}$ right $54.5 \mathrm{fps}$}

Figure 1. Distribution of mines from canister

Canisters are launched simultaneously from each side of the aircraft. Canisters on one side of the aircraft are sequentially launched at 12.5-meter intervals along the flight path. The resulting minefield consists of two 35-meter bands of mines separated by a 70meter mine-free band. A $100-\mathrm{m}$ portion of one of the $35-\mathrm{m}$ bands is shown in Figure 2. (Although Figure 2 appears to show various symbols, each of them represents a mine.)

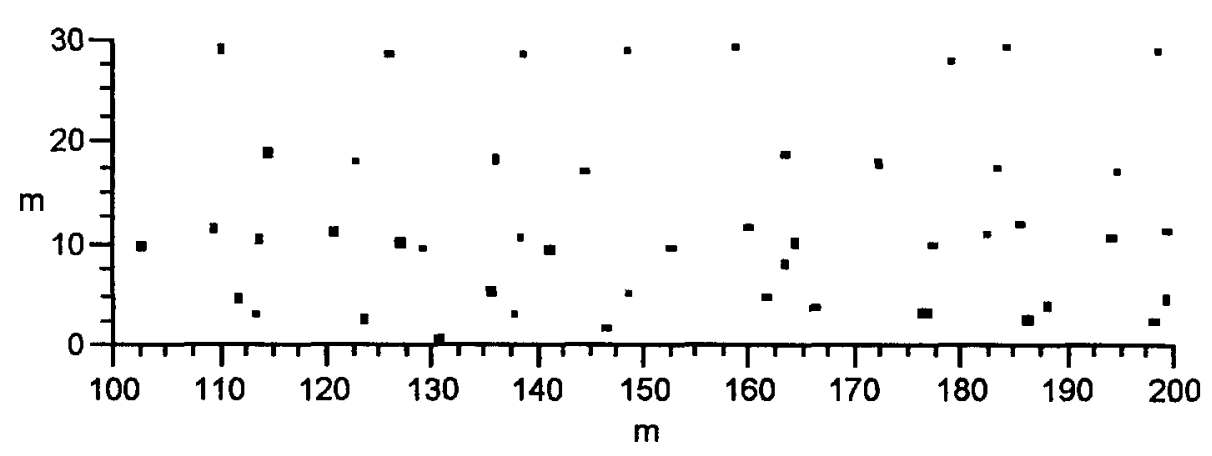


Figure 2. Example of distribution for a minestrip

Minefields were generated using a computer model that computed the pattern produced by launching the canisters at 12.5 -m intervals. To mimic random variations, the model incorporated a normally distributed random error with a standard deviation of $5 \%$ in range and 5 degrees in azimuth. An example pattern is shown in Figure 2.

\section{II.A.2. Minefield Design}

The blocking minefield design was used for this analysis because it is the most breach-resistant. This tactical employment is designed to produce maximum delay and casualties to an attacker attempting to breach and is always protected by anti-personnel mines. It is also constructed with sufficient depth to counter the rocket-propelled line charge. The standard US design consists of two volcano laydowns in depth, one immediately behind the other. The resulting field contains four 35-meter strips separated by unmined areas - with the full depth of the resulting field being approximately 300 meters. This type of minefield is shown in Figure 3. One helicopter volcano load can install a 500-meter wide blocking minefield within 30 seconds.

\section{Laydown pattern - minefield}

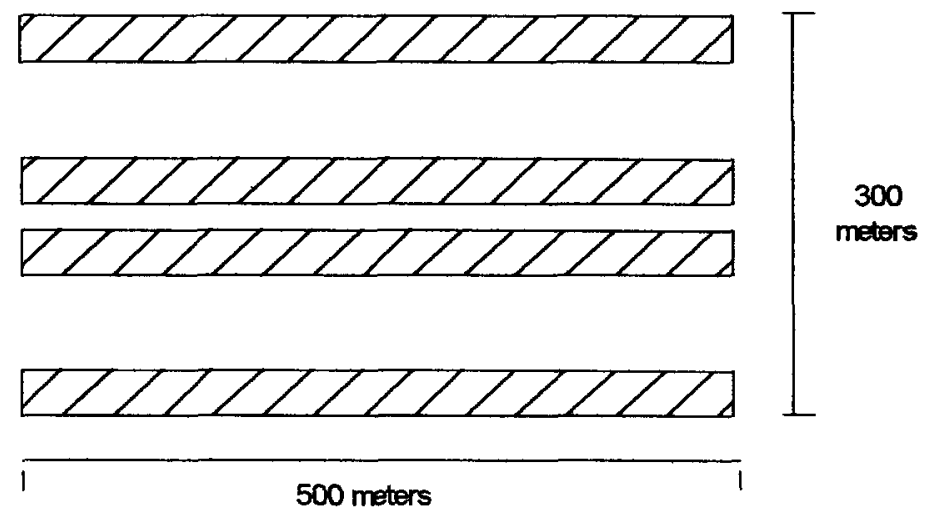

Figure 3. Volcano minefield pattern 


\section{II.B. Movement parameters}

Parameters related to mine movement were investigated next. Because no such system as the Self-Healing Minefield currently exists, we needed to come up with a concept so that we would know how to evaluate it. We looked at the system in general terms, not limiting ourselves to designs that are physically robust, in order to give ourselves a notional system to start with for looking at various mine parameters. Each mine has a movement (or "jump") distance, a sensing distance, and a simple decision algorithm to determine if it must move. Several concepts were initially examined and the concept that seemed best able to maintain the minefield, described in the following paragraphs, was used for further study.

The mines are assumed to be able to appraise their environment within some number of touching, non-overlapping angular sectors (i.e., quadrants, octants, etc.). It is assumed that a mine detects its neighbors by receiving a radio signal from them. The mine recognizes the contents of a sector in such a way that it is not aware of each neighbor in a sector, only of the total signal strength received from that sector. When a mine moves, it jumps along the centerline of the sector that indicates that motion is appropriate.

It is also assumed that jumps are 'consumed' as they occur (a reasonable assumption if the jump mechanism consists of explosive squibs, for example). If a mine has 8 sectors, i.e., looks at its environment in octants, once it has moved in a certain direction, the squib that was fired is not available for future movement. Because it is also assumed that the mines rotate arbitrarily when they move, the used squib is unlikely to correspond to the same direction it did when it was fired. It has the consequence that there is some direction in which the mine cannot move. As a mine moves more times, more squibs are fired and it becomes increasingly likely that a mine will not be able to move in the required direction because its jump mechanism for that direction has been consumed. We assumed that the mines are one-sided, i.e., the squibs are only on the bottom, and that the mine will land on the bottom after each jump.

We assumed that each mine receives signals from surrounding mines. Reception direction is based on sectors, with the mine summing all signals received within each sector. The initial signal strength establishes the basecase. Jump distance and maximum sensing range are $10 \mathrm{~m}$.

If the signal strength in one sector changes (i.e., decreases because a mine has been removed, destroyed, or detonated), the mine compares the summed sector signal against two values, a minimum signal change and a maximum signal change. If a signal change is below the minimum, the removed mine is beyond jump range; if it is above the maximum signal change, the mine that was removed was too close so that a jump would carry this mine beyond it. So the mine will jump if the removed mine is not too close-where it would jump beyond-or too farwhere it could not jump far enough.

Magnetic fused antitank mines will detonate anywhere under the body of a tank, thereby having an effect against the full width of the tank. The mine, therefore has a radius of effect equivalent to $1 / 2$ the width of the target vehicle (i.e., approximately 1.5 meters). This establishes 
the mine's area of influence on the ground. Any vehicle whose center crosses the mine's area of influence is attacked by the mine (becomes a target). We imposed the condition that the replacement mine must jump to a place where it affects a portion of the original mine's area of influence. This occurs whenever its area of effect intersects any portion of the first mine's area of influence. The jumping mine must therefore land at a distance less than or equal to twice its radius-of-effect from the original mine position. If the mine can detect out to 10 meters and a mine between 4 and 10 meters is removed, it should jump a distance of 7 meters. From an angular point of view, we considered a mine that has the ability to sense and to move in octants, i.e., can move in eight different directions.

\section{II.B.1. Technical analysis}

The effectiveness of a minefield was determined by constructing a Monte Carlo computer simulation, written in Fortran, to establish a minefield, breach it, and let the mines move. The minefield is then breached again and heals itself again. Breaching/ healing are repeated. After each healing we count the number of mines remaining in the breach lane, the fraction of minefields that have clear breach lanes, and how many times the breach/heal cycle must be repeated before the lane is cleared.

The following figures $4 \mathrm{a}-\mathrm{f}$ illustrate the mechanics of the model. The figures show the mines in one of the 35-m deep bands of a Volcano minefield. The other three bands are statistically independent.

Figure 4a shows a 100-m wide portion of one of the four strips of the 500-m wide Volcano minefield as the mines originally lie on the ground. A 5-m breach lane will be made in the center of the minefield, as shown in Figure $4 \mathrm{~b}$.

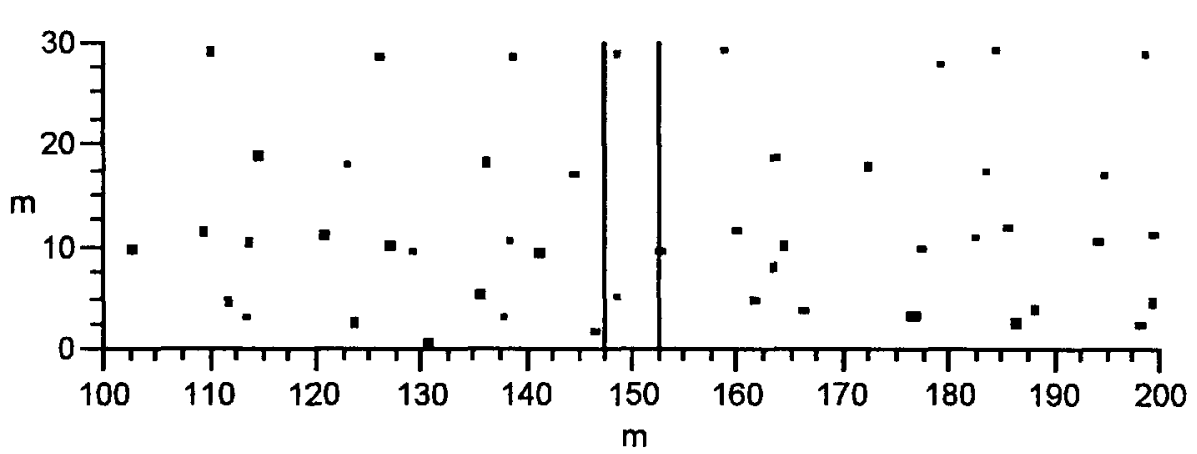

Figure 4a. Initial distribution of mines in $100-\mathrm{m}$ wide strip 


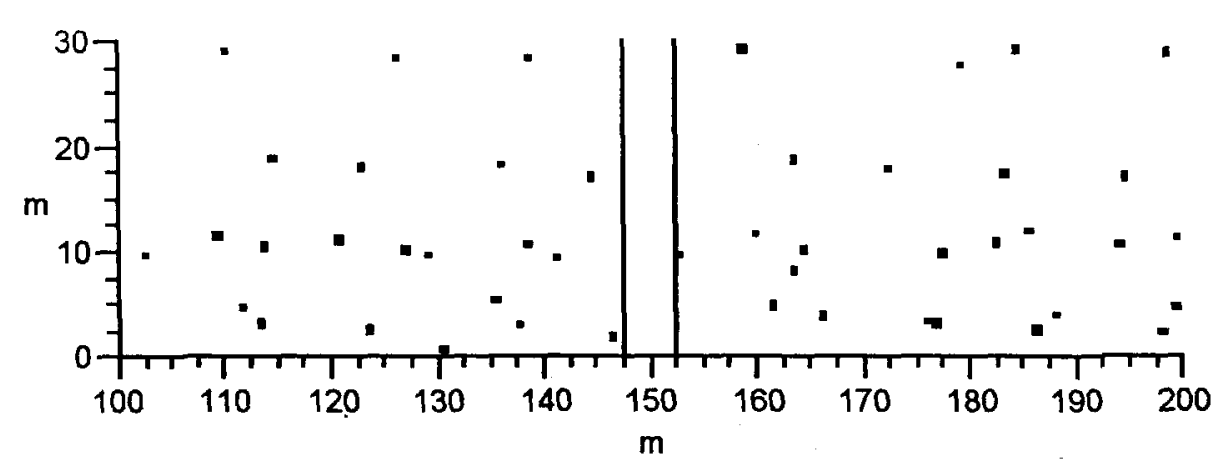

Figure 4b. Distribution of mines after first breach

Notice that 2 mines have been removed from the lane-one about $5 \mathrm{~m}$ into the lane, and the other near the end $(30 \mathrm{~m})$ of the lane.

Next the remaining mines, sensing the removal of some neighbors, jump. As soon as those have moved, the holes that they have created will also be filled in, etc. The overall effect is to move the minefield in from the edges toward the center. In this case, we have chosen that a mine detecting the loss of a neighbor $4-10 \mathrm{~m}$ away will jump $7 \mathrm{~m}$.

Two mines have moved into the lane (Figure 4c). Notice there has been a lot of rearrangement on the right side of the breach and none on the left side. The lack of movement on the left side is a consequence of there being so few (two) mines in the breach lane and their removal does not meet the jump criteria of their neighbors to the left. Statistics decrees it unlikely that the other 35-m deep bands of the minefield will show behavior identical to this. Again this lane is breached, and again the mines move, giving the arrangement shown in Figure 4d of mines on the ground. This time only one mine has moved into the breach lane. Again, all movement has been on the right side of the breach lane.

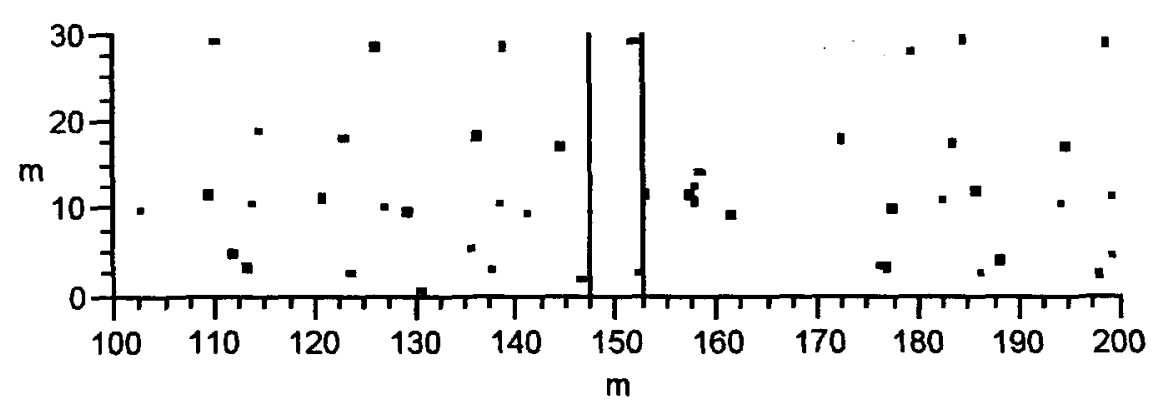

Figure 4c. Distribution of mines after first healing 


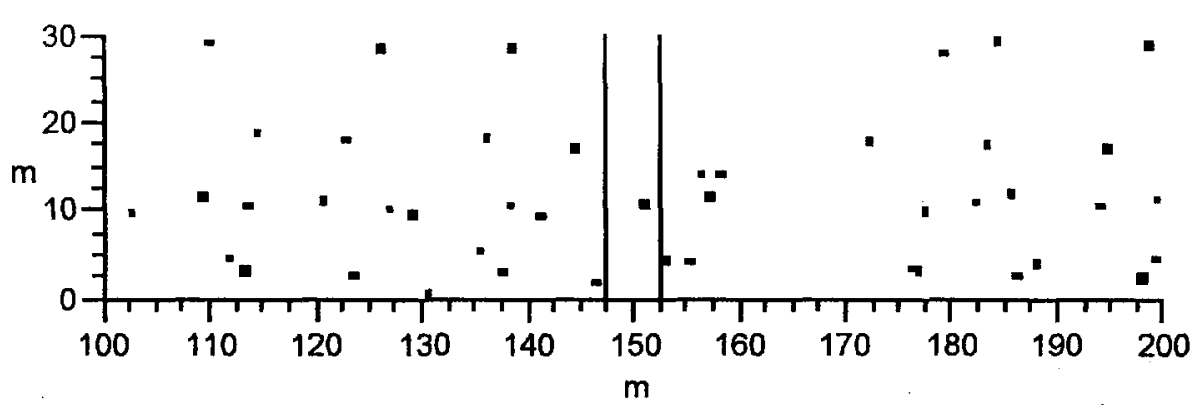

Figure $4 \mathrm{~d}$. Distribution of mines after second breach and healing

Notice that a lane has opened up between about 160 and $170 \mathrm{~m}$. Such lanes started to form about half the time (sometimes as far away from the breach lane as 70-100 $\mathrm{m}$ ) after a few healings of the minefield. Although this lane exists, breaching forces have no way of knowing about it. In order to ensure that there are no mines there, they would have to send a breaching unit to look (which takes as long as a breach). They have no cue suggesting to them that they should look where the gap is and to them it is the same as any other part of the minefield. Furthermore, although a gap has formed here, there is no guarantee that such a gap has formed in the other three bands of the minefield. If such a gap has formed in other bands, it is unlikely that it would be in the same position as the gap in this 35-m band.

This lane has arisen through continued movement of the mines toward the breach lane. After the first breach and the first healing of the minefield, a gap formed near the mine at about $170-\mathrm{m}$, so that there are no neighbors within $10 \mathrm{~m}$ to its left. Using our simple scheme, if there is no signal in a sector, a mine will never move in that direction (because motion is dependent on a signal decrease). When this mine moves, therefore, there is no other mine to jump in to replace it. Also, recall that we have chosen to study a fairly simple system-a smarter minefield would close such gaps as these.

Some of the figures, such as Figure $4 \mathrm{~d}$, show that at times the mine density in the lane (and immediately next to it) is sparse enough that it might appear that tanks could maneuver around the mines. Extensive testing at Ft. Hunter-Liggett prior to the initial fielding of the Volcano system demonstrated that tank crews were unable to maneuver around mines successfully even when they saw them. Because tank drivers cannot see the ground directly in front of them and because tanks are clumsier vehicles than, say, bicycles, this is not a feasible approach.

The lane is breached for a third time, the mines move again. Figure $4 \mathrm{e}$ shows their arrangement. 


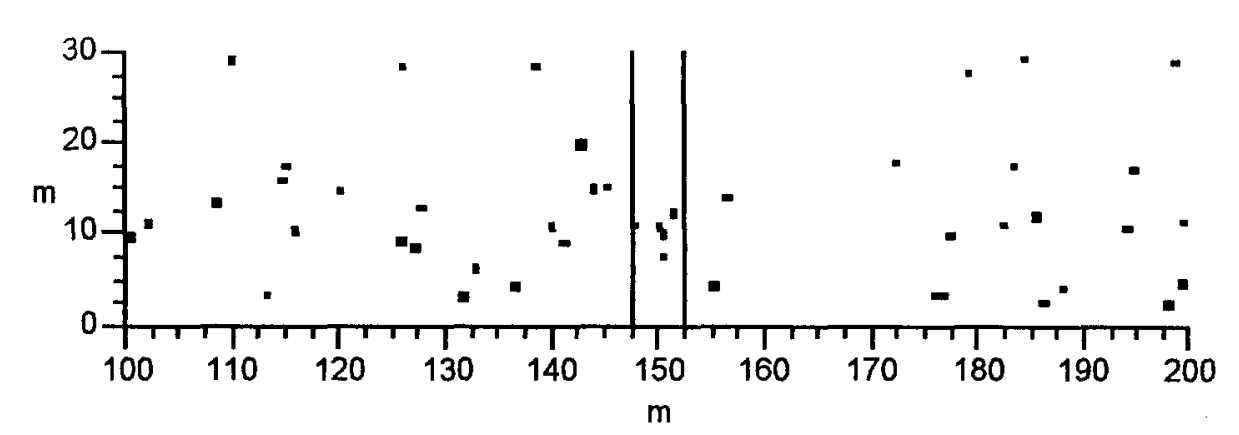

- Figure 4e. Distribution of mines after third breach and healing

This time there are five mines in the breach lane, and the mines on the left side of the breach lane have also moved. The gap on the right side of the breach lane is getting bigger, and clearly, very soon no more mines will be able to heal the breach from that direction.

Without showing every step leading up to it, the following figure, $4 \mathrm{f}$, shows the minefield after it heals itself after the sixth breach.

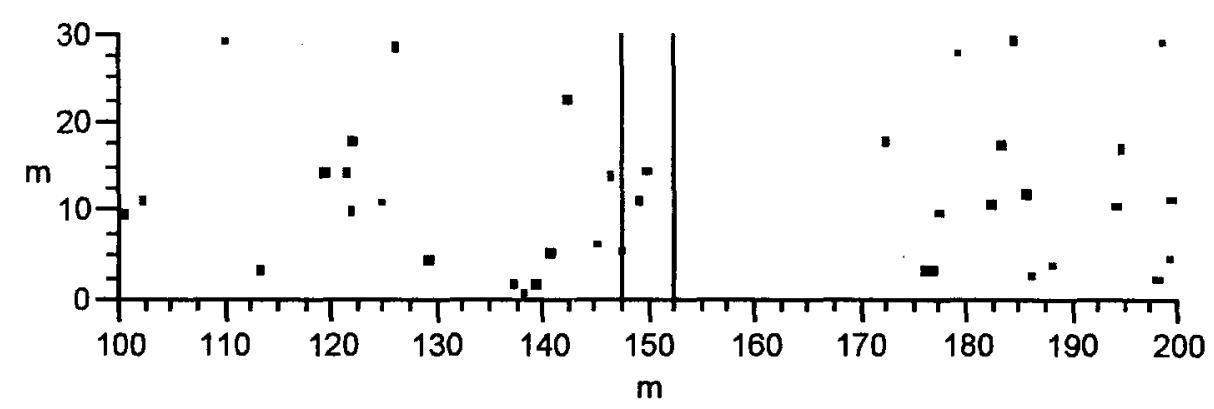

Figure 4.f. Distribution of mines after sixth breach and healing

There has been significant motion on the left side of the lane and it is clear that the right side of the lane will no longer contribute to the continued existence of mines in the lane. This run was stopped at this point-we do not know how many more times a breach followed by mine rearrangement would be necessary before a lane could be established.

A number of different combinations of jump criterion (i.e., minimum and maximum distance at which a mine must be removed in order for a neighbor to jump) and jump distance were examined. The following table shows the results.

Table 1 shows the percent of time a clear lane exists (i.e., the probability that a lane exists) where the enemy is trying to effect a breach in the examined strip only-not through the entire minefield - of the minefield after $1,2, \ldots 6$ breaches and healings for four different combinations of jump criterion and jump distance. For the first set of values, with a 7-m jump distance, a clear lane begins to form $10 \%$ of the time after only 2 breaches and over $25 \%$ of the time after 6 breaches. As the jump distance increases, the 
probability of a clear lane decreases. Although one initial constraint was that mines will jump no more than $10 \mathrm{~m}$, curiosity provoked examination of even larger values for jump distance, which showed that the probability of a clear lane continues to decrease out to jump distances of $12-13 \mathrm{~m}$ and then begins to increase again. It is likely that this corresponds to the $12.5-\mathrm{m}$ spacing of the canister launches from the helicopter. The launch spacing shows clearly in the form of the minefield-mines dropped at $12.5-\mathrm{m}$ intervals show up on the ground as vague clusters about $12.5 \mathrm{~m}$ apart. A jump distance of 12-13 $\mathrm{m}$ allows mines from one cluster to jump into the next.

Table 1. Percent probability that a lane is clear of mines as a function of jump parameters

\begin{tabular}{c|llllll}
$\begin{array}{c}\text { Inner sense dist / } \\
\text { Jump dist / }\end{array}$ & \multicolumn{5}{|c}{ Number of Sequential Breaches } \\
Outer sense dist (m) & $\mathbf{1}$ & $\mathbf{2}$ & $\mathbf{3}$ & $\mathbf{4}$ & $\mathbf{5}$ & $\mathbf{6}$ \\
\hline $\mathbf{4 / 7 / 1 0}$ & 5.2 & 9.6 & 13.6 & 17.8 & 23.6 & 27.5 \\
$\mathbf{5 / 8 / 1 1}$ & 2.6 & 5.0 & 5.8 & 7.8 & 10.0 & 11.5 \\
$\mathbf{6 / 9 / 1 2}$ & 1.8 & 2.4 & 3.8 & 5.6 & 7.4 & 8.3 \\
$\mathbf{7 / 1 0 / 1 3}$ & 1.0 & 1.8 & 2.6 & 2.8 & 2.8 & 3.0
\end{tabular}

Several other methods for optimizing minefield parameters were also looked at in a cursory manner with the intention of continuing work on those that appeared particularly useful. Two of these are presented here.

\section{II.C. Enemy breaching}

The anti-personnel mine in the mixed scattered minefield serves to protect the anti-tank mines from a "cheap" breach - a dismounted breach made by soldiers simply moving through the minefield at a quick pace and placing explosive charges on each mine to destroy them. At normal engagement ranges this would be the technique of choice if the anti-personnel mines were not present. A defender would have a limited number of anti-personnel weapons that could range to the minefield. Engagement times for those systems (including time of flight of the projectile) would be sufficiently long that a soldier employing the normal 3-5 second rush procedure used under direct fire is relatively invulnerable. As long as the breach can be completed before artillery or mortars could adjust in on the moving target, this technique promises the highest probability of success.

Dismounted breaching employs dismounted soldiers moving in a formation through the mined area placing charges on surface mines found within a lane being 
breached. Simuitaneously, other soldiers mark the two edges of the cleared lane with flags or other markings. This is the technique of choice for surface anti-tank minefields at normal ranges from defending battle positions $(1.5$ to $2.5 \mathrm{~km})$. It is commonly called the "pop \& drop" method. Although this is a US tactic, it is also generally used for breaching an anti-tank minefield.

\section{II.C.1. Movement and Breaching Speeds}

Some basic calculations were necessary in order to model the breaching operation effectively. These involved identifying logical methods to counter the minefield and applying dismounted movement rates to the breaching teams. Planning movement rates are shown in Table 2.

Table 2. Dismounted movement table

\begin{tabular}{|l|l|l|l|}
\multicolumn{1}{c}{ Entity } & \multicolumn{1}{c}{ Technique } & \multicolumn{1}{c}{ Ground Speed } & \multicolumn{1}{c|}{ Movement Rate } \\
\hline Individual & Walk & $4 \mathrm{mph}$ & $1.8 \mathrm{~m} / \mathrm{sec}$ \\
\hline & Run & $6.7 \mathrm{mph}$ & $3 \mathrm{~m} / \mathrm{sec}$ \\
\hline Formation & Cautious & $1.125 \mathrm{mph}$ & $0.5 \mathrm{~m} / \mathrm{sec}$ \\
\hline & Rush & $4.5 \mathrm{mph}$ & $2 \mathrm{~m} / \mathrm{sec}$ \\
\hline & $3-5 \mathrm{sec}$ rush* & $0.45 \mathrm{mph}$ & $0.2 \mathrm{~m} / \mathrm{sec}$ \\
\hline Pop \& drop breach & Not under direct fire & $0.74 \mathrm{mph}$ & $0.33 \mathrm{~m} / \mathrm{sec}$ \\
\hline & Under direct fire** & $0.23 \mathrm{mph}$ & $0.1 \mathrm{~m} / \mathrm{sec}$ \\
\hline
\end{tabular}

* Ave. rush, $4 \mathrm{sec}$ and $6 \mathrm{~m}$, time between rushes $15-30 \mathrm{sec}$, one rush cycle $=30 \mathrm{sec}$ and $6 \mathrm{~m}$

** Can only travel 3 meters in 4 seconds looking for mines, one rush cycle becomes 30 $\mathrm{sec}$ and $3 \mathrm{~m}$

Breaching soldiers move at a fast walking pace to complete their task before enemy artillery can be adjusted onto them. This is the "not under direct fire" category. If receiving direct fire, they change to a rush technique, where they move in 3 to 5 second rushes.

\section{II.C.2. Breaching}

A breaching party is a dismounted squad. This provides organization and leadership in the minefield, along with some redundancy and local security. Breaching drills are based on a 6-man dismounted squad to accommodate the normal battlefield squad strength.

The basic dismounted technique employed against surface anti-tank mines is the "pop \& drop" technique. In this technique, the breacher moves as quickly as possible while visually scanning the ground to his immediate front. When he locates a mine, he places a primed charge against it without disturbing the mine. 
Breaching charges are typically one pound blocks of high explosive. They may be individually primed so that the breaching soldier can ignite each fuse upon charge placement on a mine, or detonating cord (or shock tube) may link them so that all are detonated simultaneously.

A following soldier unrolls a line main of either detonating cord or shock tube down the lane centerline. Another following soldier connects branch lines from the charges to the line main. Upon exiting the lane, the squad leader detonates the charges.

To provide sufficient side clearance for buttoned-up armored vehicles to drive through, the standard breach lane is 5 meters wide. This width is cleared by three soldiers in a " $\mathrm{V}$ " formation, each scanning a two-meter strip of ground with 1/2-meter overlap between scanned areas. A fourth soldier (the supervisor) controls the direction of the breach and acts as quality control to ensure no mines are missed and that charges are placed properly.

When not under fire, the breach members move at a slow walk, stopping briefly at each mine. When under direct fire, they move in short rushes while planning their movements to stop next to mines so that they can place charges while lying prone.

\section{II.C.3. Basic Breaching Formation}

One breach lane requires a squad of six, not including lane-marking personnel. The four-man breaching team consists of a three man " $V$ " formation, followed by the squad leader who maintains alignment, directs individual movement, checks work, and acts as safety NCO. The remaining two squad members follow installing the line main and connecting the branch lines. They also act as replacement breachers. Any additional squad members follow and provide local security. This is depicted in Figure 5. 


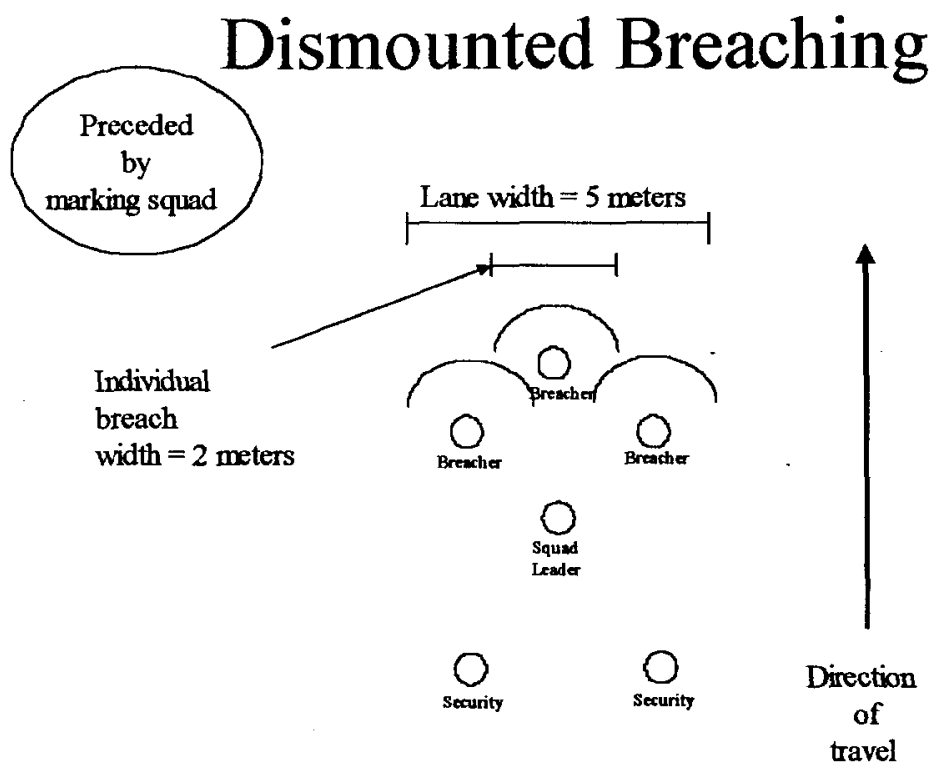

Figure 5. Dismounted breaching

\section{II.D. Breaching Counters to the Self-healing Minefield}

Discussions with breaching experts consisting of infantry and engineer officers identified three techniques that might be effective against a self-healing minefield. While these tactics are not affiliated with any particular nation's military, they are those most likely to successfully counter the Self-Healing Minefield. These consisted of repeated breaching of a single breach lane, a parallel breach technique where lanes were breached on both sides of the eventual lane (so that the mines in the center would jump to the sides) and then proofing the center lane, and a wide-lane technique where many adjacent five-meter lanes were breached simultaneously. Breach timing for these techniques follows.

\section{II.D.1. Single sequential breach lane technique}

This technique involves repeated breaching of the same lane. An initial breach is made, destroying mines within the lane. The remaining mines move to fill the lane with replacements. A following squad repeats the breach process. This can continue through many successive squads.

As the breach teams don't know precisely where each strip begins and ends, they use breach movement for 40 meters for each strip. Figure 6 illustrates this technique for two squads assuming a five minute interval between squads to allow charge detonation on a mine strip. 


\section{Sequential Breaching}

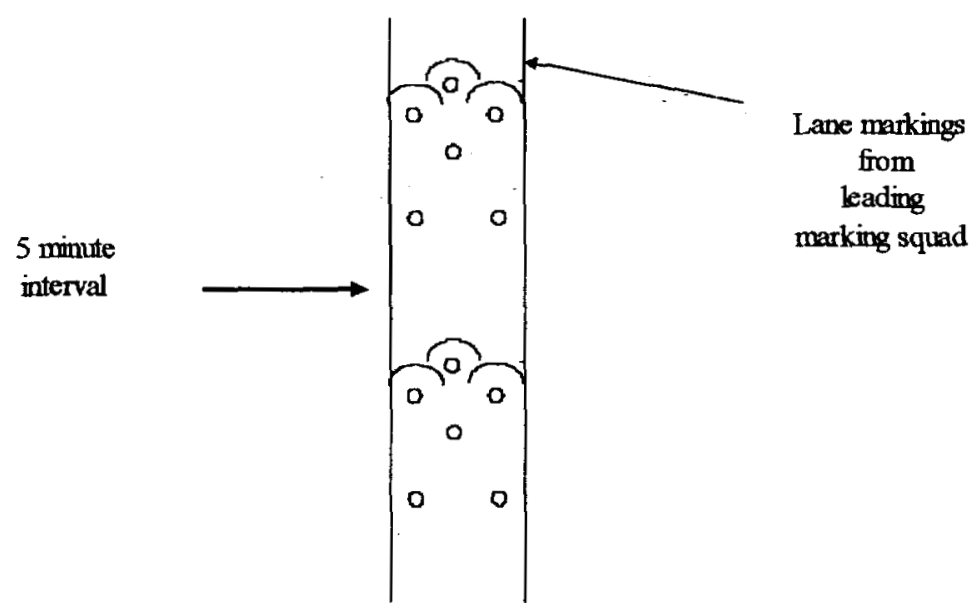

Figure 6. Sequential breaching

A rough calculation of breaching time can be made for the two cases, under direct fire and not under direct fire (obviously there are intermediate times, where the squad switches between the movement modes). The following calculations are rough breaching times for the lead squad. As other squads take the same amount of time at five minute intervals, simply adding five minutes for each additional squad will provide time for the sequential breach.

Not under direct fire:

$0.33 \mathrm{~meter} / \mathrm{sec}$ for $40 * 4$ meters of breaching $=485 \mathrm{sec}$

$0.5 \mathrm{~meters} / \mathrm{sec}$ for 140 meters traveling $\quad=280 \mathrm{sec}$

Two minutes for final charges to detonate $\quad=120 \mathrm{sec}$

Total $=895 \mathrm{sec}$ (approximately 15 minutes)

Under direct fire:

$0.1 \mathrm{~meter} / \mathrm{sec}$ for $40^{*} 4$ meters of breaching $=1600 \mathrm{sec}$

$0.2 \mathrm{~meter} / \mathrm{sec}$ for 140 meters of traveling $=700 \mathrm{sec}$

Two minutes for final charges to detonate $=120 \mathrm{sec}$

Total $=2420 \mathrm{sec}$ (approximately 41 minutes) 


\section{II.D.2. Parallel breach technique}

This technique calls for two parallel lanes, 5 meters apart. The mines in the center will jump into the cleared lanes. The expectation is that clearing the side lanes twice, followed by proofing the center, will provide a five-meter center cleared lane.

The technique is for a lane marking squad to cross through the minefield marking each side of a five-meter lane. If necessary, they could use a spacer cord to guarantee the five-meter separation between edge flags. Immediately following the marking party, two breaching teams breach five-meter wide lanes on the outside of each row of flags. As soon as the breaching teams have cleared the first mine strip, they detonate mines found. The mines in the lane between the lines of markings then respond to the missing mines to each side, and jump out of the center lane. Two additional teams then wait for the detonations and the subsequent jumping into the lanes of replacement mines, and repeat the operation. A final breach team follows the second set of teams to proof the center lane. This is illustrated in Figure 7.

\section{Parallel Lanes}

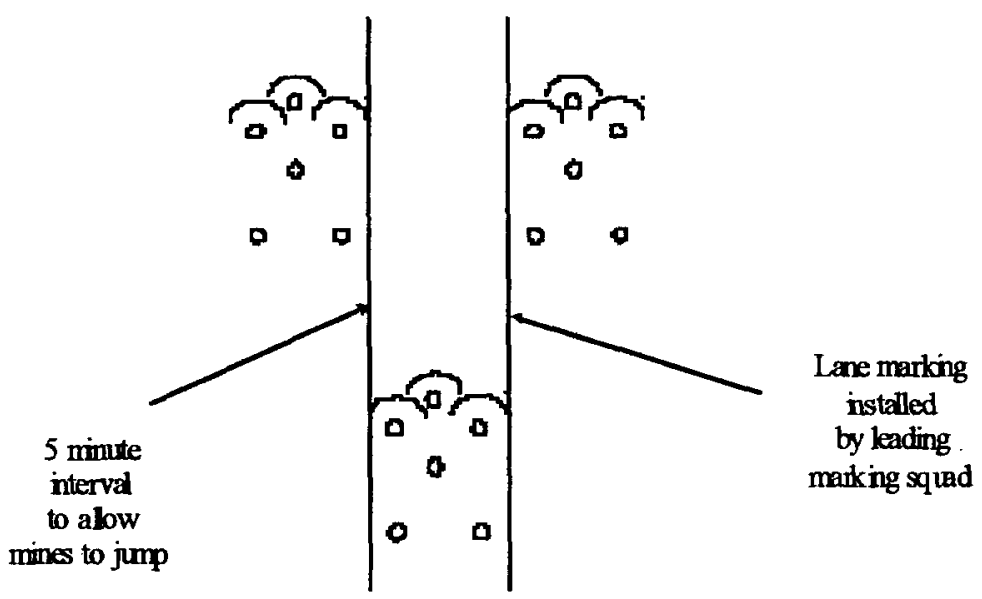

Figure 7. Parallel lanes

The rough breaching rate calculations follow for the two conditions, under direct fire and not under direct fire.

Not under direct fire: The second teams must wait for the lead teams to clear the first strip before starting to move. As the lead teams move at 0.33 meter $/ \mathrm{sec}$ for 40 meters to breach this strip, this requires 120 seconds. The team then must wait 3 minutes for the mines to detonate. The second teams follow the first with a time spacing of 5 
minutes. The proofing team follows the second teams after waiting a similar 5 minutes. The total time for this technique while not exposed to direct fire is 15 minutes (from the squad breaching example above) plus 5 minutes for the second side breaching team to complete, plus a final 5 minutes for the proofing team to complete, or a total of 25 minutes.

Under threat of direct fire: The same logic holds, however the lead teams require 400 seconds to clear the first strip. Waiting an additional 3 minutes for the mines to detonate results in the second teams beginning 9.7 (or 10) minutes after the lead teams. The proofing team also follows after a 10-minute wait. The total time for this technique while exposed to the threat of direct fire, is 41 minutes plus 10 minutes plus 10 minutes, or approximately 60 minutes.

\section{II.D.3. Wide lane breach technique}

This technique uses multiple breaching teams crossing through the minefield adjacent to each other, thus producing a wider lane. Again, the lane-marking squad marks the eventual clear lane to aid alignment of the breaching squads. Instead of a fivemeter front, all squads move together, so three breaching squads would produce a 15 meter clear zone, while five breaching squads would produce a 25 -meter clear zone. The speed is considered to be the same as for a single breaching squad (even though coordination would require a slower operation - all squads must be clear of a strip before any mines could be detonated). This technique is illustrated in Figure 8.

\section{Wide Lanes}

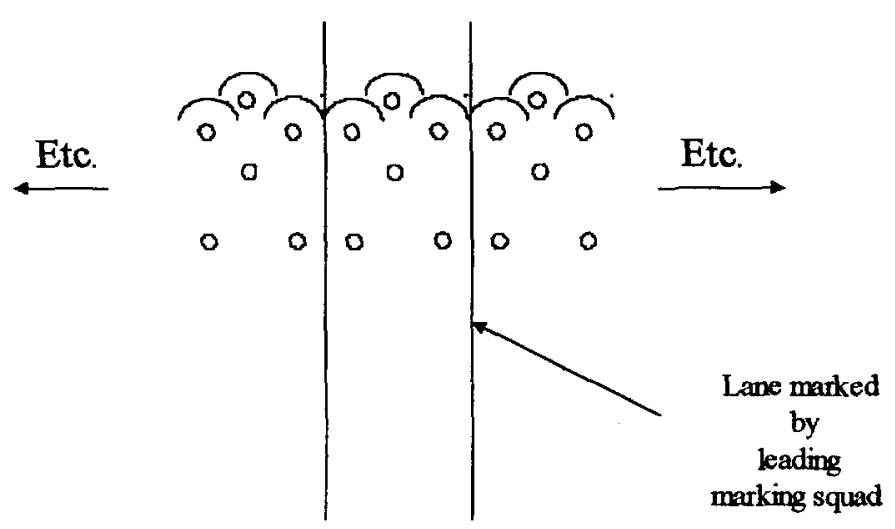

Figure 8. Wide lanes breaching technique 
As all squads breach at the same time, the calculations are the same as for a single squad making a single lane.

Not under direct fire:

$0.33 \mathrm{~meter} / \mathrm{sec}$ for $40 * 4$ meters of breaching $=485 \mathrm{sec}$

$0.5 \mathrm{~meters} / \mathrm{sec}$ for 140 meters traveling $\quad=280 \mathrm{sec}$

two minutes for final charges to detonate $\quad=120 \mathrm{sec}$

$$
\text { Total }=895 \mathrm{sec} \text { (approximately } 15 \text { minutes) }
$$

Under direct fire:

$0.1 \mathrm{~meter} / \mathrm{sec}$ for $40^{*} 4$ meters of breaching $=1600 \mathrm{sec}$

$0.2 \mathrm{~meter} / \mathrm{sec}$ for 140 meters of traveling $=700 \mathrm{sec}$

Wait for final charges to detonate $\quad=120 \mathrm{sec}$

Total $=2420 \mathrm{sec}$ (approximately 41 minutes)

\section{II.E. Breaching Analysis}

The primary output from the technical model is the minefield density gradient in the vicinity of the breach lane after minefield "healing." This was used as an input to the operational model. The Fortran minefield model used to generate self-healing minefield arrays for the tactical (JCATS) model was used to assess the utility of the different breach techniques.

The following Figures 9a-e illustrate the concept of breaching parallel lanes. In this example, the jump criterion is that a mine moves if a neighbor has disappeared from a range 4-10 $\mathrm{m}$ away, and jump distance is $7 \mathrm{~m}$. Again, the mines considered have the ability to sense and to move in eight different directions.

Figure $9 \mathrm{a}$ is one $35-\mathrm{m}$ deep band of the original minefield, which consists of 4 such bands. Notice that there are 2 mines in the central lane but this time the tactic is to clear the two outer lanes, in the hopes that the central lane will clear itself. 


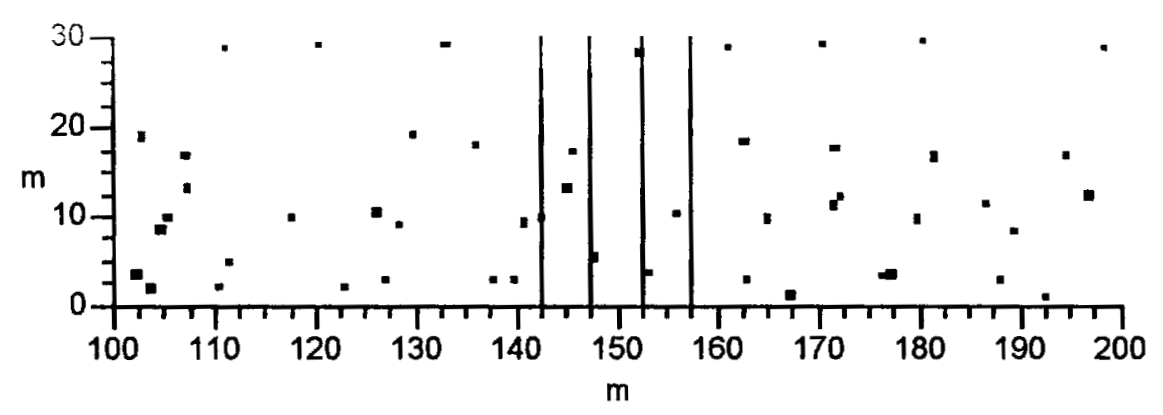

Figure 9a. Original minefield distribution

The breach has been completed (Figure 9b). The central lane has retained its 2 mines, and the two outer lanes are cleared.

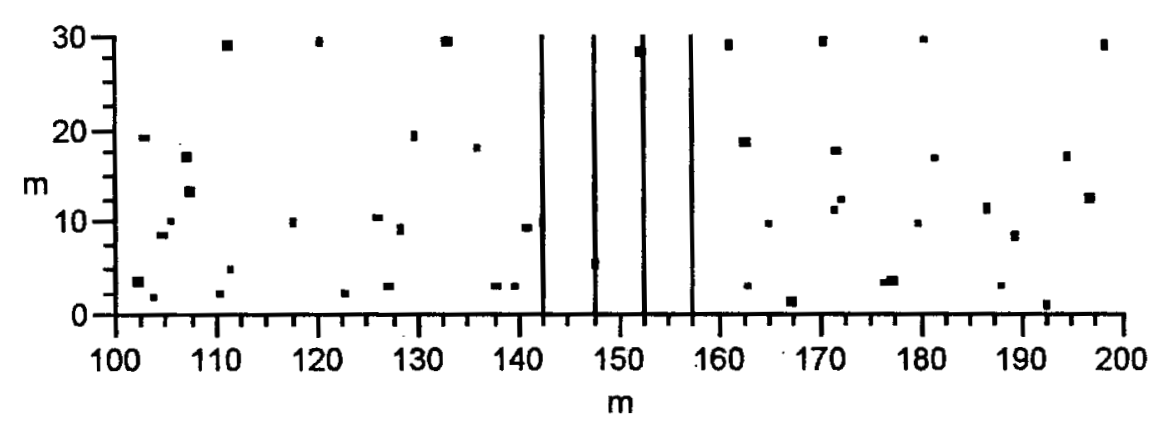

Figure $9 b$. Minefield after breach is completed

After the first rearrangement (Figure 9c), we see that one of the mines from the center lane has, in fact, moved out of the lane. Notice that although there was a fair amount of rearrangement on the right side of the breach lanes, none of those mines entered any of the lanes. (The cluster of mines near coordinates $(165,10)$ is a consequence of the statistical nature of the minefield's behavior.)

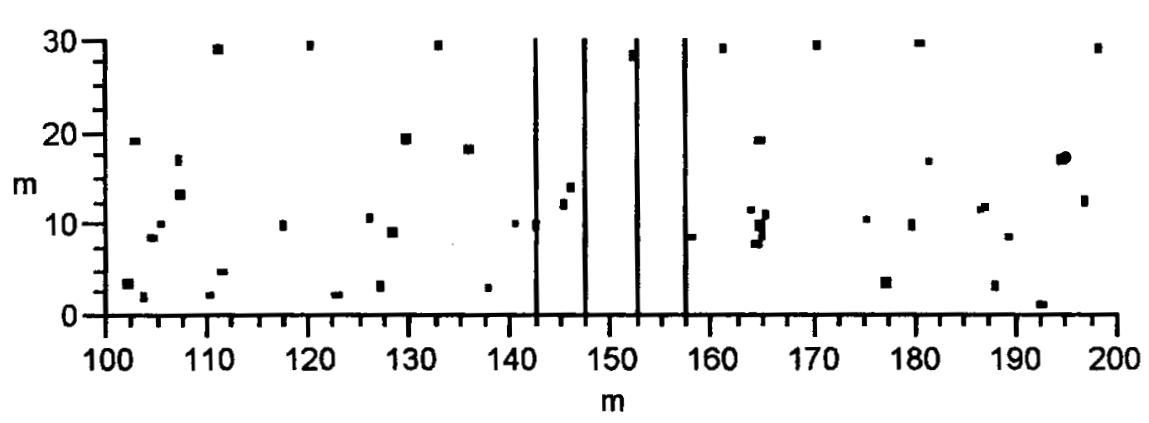

Figure 9c. Minefield distribution after first rearrangement 
Figure 9d shows the minefield after the second breach and the second healing. There will be no more movement on the right side of the minefield, since there are no mines in the right breach lane.

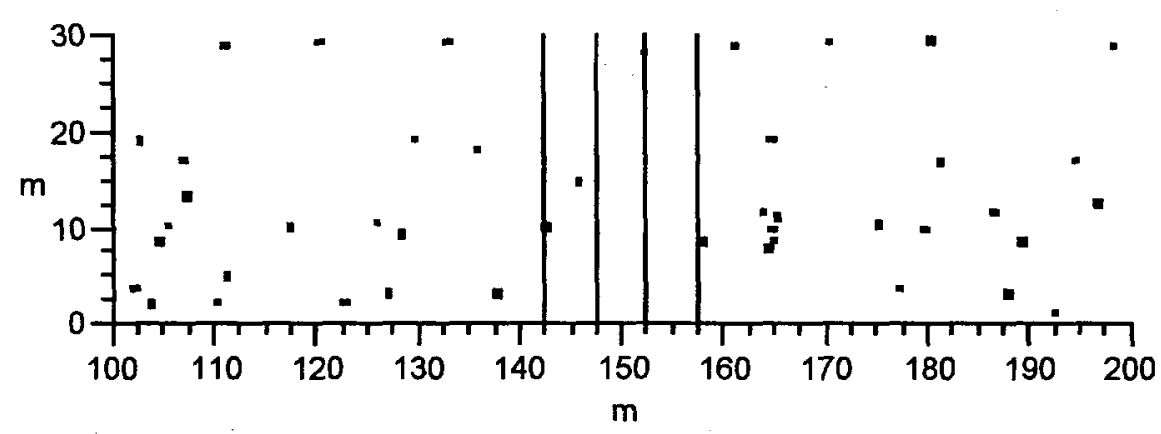

Figure 9d. Minefield after second breach and healing

Figure $9 \mathrm{e}$ is the minefield after the third breach and the third rearrangement. Notice that there are two mines in the center lane, as there were in the beginning. In this case, though, if the breachers choose to proof the center lane at this point, it is possible that they will have a clear lane. It is also possible that the mine at position $(141,10)$ will be caused to move into the center lane due to the removal of the mine at position $(148,14)$.

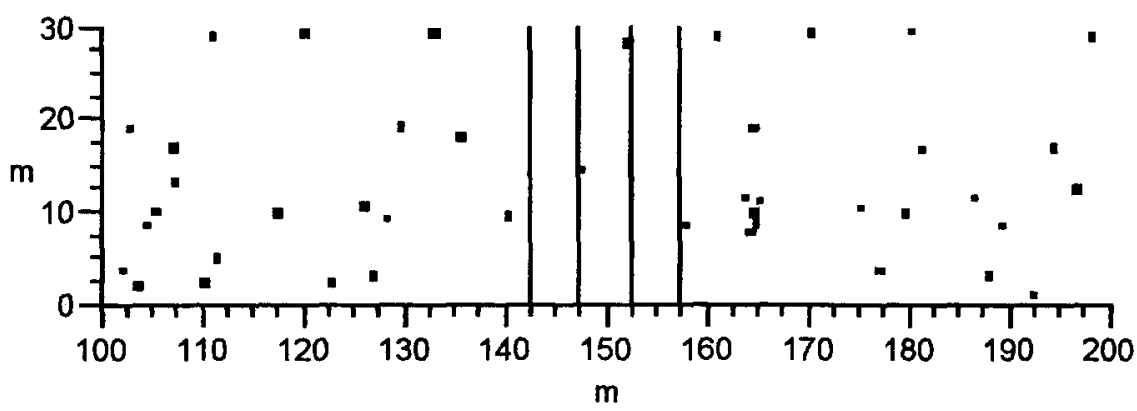

Figure 9e. Minefield after third breach and healing

Ten variations of the three basic techniques were examined. Measures of effectiveness are the average number of mines remaining in the lane and the probability of a mine-free lane. Only one technique produced an acceptable lane.

Table 3. Breach analysis results 


\begin{tabular}{|l|l|l|l|l|}
\hline Technique & $\begin{array}{l}\text { Breaching } \\
\text { Force }\end{array}$ & $\begin{array}{l}\text { Average \# } \\
\text { mines } \\
\text { remaining }\end{array}$ & $\begin{array}{l}\text { Probability } \\
\text { of no mines } \\
\text { remaining }\end{array}$ & $\begin{array}{l}\text { Time to } \\
\text { conduct } \\
\text { breach (no } \\
\text { fire/direct } \\
\text { fire) }\end{array}$ \\
\hline Sequential & 6 squads & 15 & $0.043 \%$ & $\begin{array}{l}35 \mathrm{~min} / 80 \\
\mathrm{~min}\end{array}$ \\
\hline Parallel lanes & 3 squads & 9.9 & $0.002 \%$ & $\begin{array}{l}15 \mathrm{~min} / 40 \\
\mathrm{~min}\end{array}$ \\
\hline $\begin{array}{l}\text { Parallel lanes } \\
\text { followed by } \\
\text { proofed center }\end{array}$ & 4 squads & 16 & $0.02 \%$ & $\begin{array}{l}20 \mathrm{~min} / 50 \\
\mathrm{~min}\end{array}$ \\
\hline $\begin{array}{l}\text { Parallel lanes } \\
\text { followed by } \\
\text { double proofed } \\
\text { center }\end{array}$ & 5 squads & 17.2 & $0.05 \%$ & $\begin{array}{l}25 \mathrm{~min} / 60 \\
\mathrm{~min}\end{array}$ \\
\hline $\begin{array}{l}\text { Repeated parallel } \\
\text { lanes }\end{array}$ & 5 squads & 9.2 & $0.03 \%$ & $\begin{array}{l}20 \mathrm{~min} / 50 \\
\mathrm{~min}\end{array}$ \\
\hline $\begin{array}{l}\text { Repeated parallel } \\
\text { lanes followed by } \\
\text { proofed center }\end{array}$ & 6 squads & 14.3 & $0.1 \%$ & $\begin{array}{l}25 \mathrm{~min} / 60 \\
\mathrm{~min}\end{array}$ \\
\hline Wide lane & 4 squads & 8.8 & $0.001 \%$ & $\begin{array}{l}15 \mathrm{~min} / 40 \\
\mathrm{~min}\end{array}$ \\
\hline $\begin{array}{l}\text { Wide Lane } \\
\text { followed by } \\
\text { proofed center }\end{array}$ & 5 squads & 11.3 & $0.01 \%$ & $\begin{array}{l}20 \mathrm{~min} / 50 \\
\mathrm{~min}\end{array}$ \\
\hline $\begin{array}{l}\text { Wide lane } \\
\text { followed by } \\
\text { double proofed } \\
\text { center }\end{array}$ & 6 squads & 13.4 & $0.05 \%$ & $\begin{array}{l}25 \mathrm{~min} / 60 \\
\mathrm{~min}\end{array}$ \\
\hline Ultra wide lane & 6 squads & 0.0 & $100 \%$ & $\begin{array}{l}15 \mathrm{~min} / 40 \\
\mathrm{~min}\end{array}$ \\
\hline
\end{tabular}

The data in Table 3 are for the entire minefield - not just one 35-m deep band, but all four strips. Table 3 shows that, except for the ultra-wide lane, every method results in a probability $>99 \%$ that the lane is not clear. The only method assuring a clear lane is the ultra-wide lane, which clears both the breach lane and any mines capable of jumping into it. It is the data from Table 3 that we have used in our tactical modeling.

We recognize that this breach solution is a consequence of the properties we have assumed for the minefield. A minefield with self-organizing properties, or with mines that jump more than once in response to a change within the minefield would likely make the ultra-wide lane also unsatisfactory. 


\section{Tactical Modeling}

Tactical modeling was conducted in-house using version 1.2 of the Joint Conflict and Tactical Simulations (JCATS), a lineal descendant of JANUS. This model is a multisided, interactive, entity-level conflict simulation employing actual three dimensional terrain and physics-based movement, observation, probability of hit (Ph) and probability of kill (Pk) algorithms and data. The Joint Warfighting Center sponsors JCATS and maintains configuration control.

Unclassified weapons data was employed for this initial assessment. Initial tactical modeling was designed to model reaction to the minefield in a single, stressful scenario. The scenario was developed in conjunction with tactics and landmine warfare experts at the US Army Infantry School, the US Army Engineer School, the Dismounted Battlespace Battlelab, and the Combined Arms Center Threat Directorate. The scenario takes place on a representative section of terrain on the Korean peninsula and consists of a US dismounted infantry company blocking a high-speed avenue of approach against a North Korean mechanized rifle battalion.

Although any scenario used in JCATS is necessarily very specific, this scenario is representative of any AT-mine scenario, and results of any other AT-mine scenario are expected to be similar to those obtained here.

\section{III.A. The Scenario}

The terrain and initial positions are shown in Figure 10. Gridlines are spaced 300 meters apart, and the contour interval is 60 meters. The surface is rocky with light brush and the battle takes place in daylight with clear visibility. The defenders sit astride a ridge overlooking a highway approaching up a valley. The attackers have approached in roadmarch column formation, and have halted in a defilade attack position until prepared to attack. The minefield shown is a standard air-installed volcano blocking minefield as previously described.

Defenders (Blue force) are arrayed in three platoon positions. The force is composed of three rifle platoons, each with 3 Dragon antitank missiles, 3 designated light antitank weapon (AT-4) gunners, two $7.62 \mathrm{~mm}$ (M60) machineguns; plus ten $5.56 \mathrm{~mm}$ M16 rifles, six $5.56 \mathrm{~mm}$ squad automatic rifles (SAW), and three rifle-mounted $40 \mathrm{~mm}$ grenade launchers (M203). Each rifleman not designated as a light antitank weapon gunner also carries one AT-4. The rifle company has been augmented with one-half of the battalion's antitank platoon, which consists of three TOW antitank missile systems and three MK19 automatic grenade launchers. It is also supported by three $60 \mathrm{~mm}$ mortars and the fires of one battery (six guns) of $105 \mathrm{~mm}$ artillery. The position has a stockpile of six TOW missiles/launcher, six Dragon missiles/tracker, 1365 rounds of $7.62 \mathrm{~mm}$ ammunition/M60 machinegun, 1200 linked 40mm grenade rounds/ Mk19 launcher, and 480 high explosive rounds/mortar. Ninety personnel are deployed in prepared fighting positions on the three battle positions. 


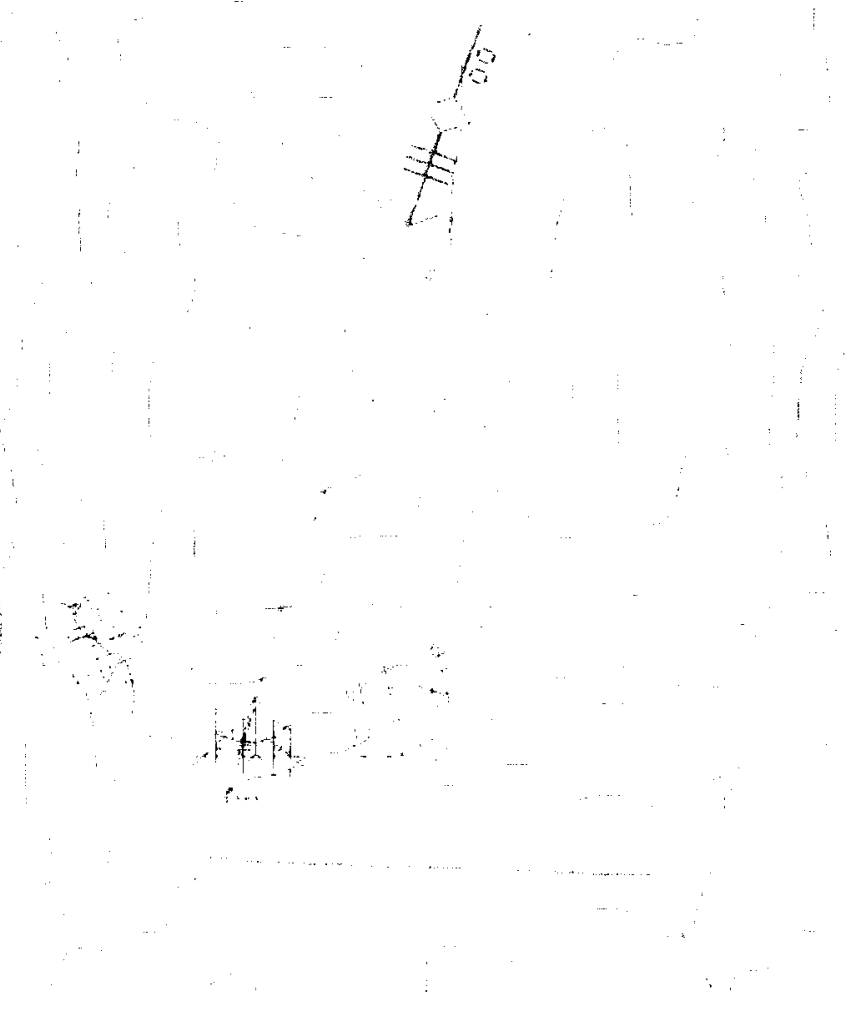

Figure 10. Terrain and initial positions of tactical scenario

Attackers (Red force) begin the battle in column in defilade. Their force, a North Korean mechanized infantry battalion, is composed of one company mounted in twelve BTR60 wheeled armored personnel carriers, and two companies carried in ZIL trucks. An armor company consisting of nine T-72 tanks augments the battalion. Each company employs nine $7.62 \mathrm{~mm}$ machineguns (PKM), eighteen $5.45 \mathrm{~mm}$ squad automatic weapons (RPK74), nine grenade launchers, six rocket-propelled grenade launchers, and sixty-six $5.45 \mathrm{~mm}$ AK74 rifles. Three hundred and twenty-four infantry are available for dismounted assault. Nine mortars and two artillery battalions (six batteries, thirty-six guns) of $122 \mathrm{~mm}$ artillery support the attackers.

\section{III.B. The Plans}

Though not a part of the vignette, Red has preceded his move with scouts who have located both the defending positions and the minefield. Based on this knowledge, Red will hold the bulk of his force and his vehicles in defilade until the minefield is breached. 
Figure 11 illustrates the breach plan. Red will attempt to breach three five-meter wide lanes through the minefield, separated by approximately 150 meters. Dismounted squads will breach and mark the lanes. Platoon weapons squads will deploy at the entrance to the breach lanes to provide close-in security to the breach teams. The mortars will fire smoke immediately in front of the minefield to conceal the breach squads from direct fire. Squads will not move out from cover until the smoke screen is established. The artillery will fire suppression on the defending battle positions. Forty rounds per gun will be fired for this purpose at the gun's sustained rate of fire.

Attacking forces in the first echelon consist of the tank company and the infantry company mounted in BTR60 armored personnel carriers. The second echelon consists of the remaining truck-mounted infantry. A tank platoon (three tanks) will lead the attack through each lane, followed by a mechanized infantry platoon (four BTR60s).

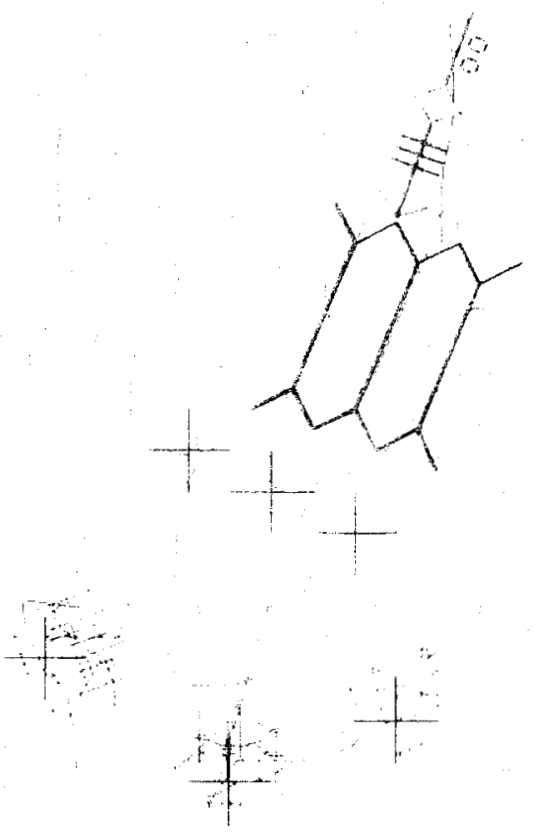

Figure 11. View of breach plan

Armored vehicles will move out through the smoke after passing through the lanes and will engage battle position targets with long range fires. Infantry carriers will 
dismount their squads approximately 400 meters from the defending positions (out of AT4 range). Artillery fires will be lifted when attackers come within 200 meters of the positions. Second echelon infantry will dismount their trucks within the smoke screen.

The defenders have a planned engagement area (EA) between their battle positions and the minefield. They have intensive interlocking sectors of fire within the engagement area. Blue artillery has an extensive pre-planned fire plan as shown in Figure 12. The intent is to fire three targets into the minefield when the breach is in progress, then shift to three targets in a potential attack position where the attacker may halt during the breach. A final pre-planned target is sited within the engagement area.

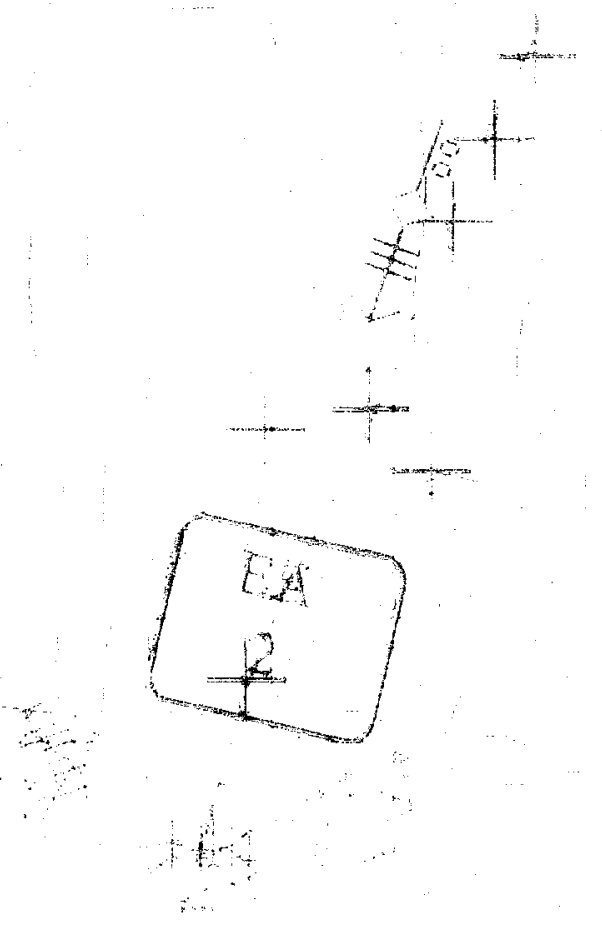

Figure 12. Blue artillery fire plan 
The minefield is tied into impassable terrain on both edges. The broken terrain limits the massing of effective long-range antitank weapons fires, consequently the primary engagement area is positioned on the defender side of the minefield. The minefield intent is to force the attackers off of the high-speed avenue and require them to deploy onto adjacent slow go terrain prior to entering the engagement area. This effectively meters the attacking force into the engagement area and allows the defender to engage a part of the attacking force at a time.

Blue will employ long-range antiarmor weapons against armored targets as they appear. Blue realizes that it is unlikely they will be able to place effective direct fires on breaching forces or on passing vehicles in the breach lanes, as the minefield will be obscured with smoke. Blue will employ mortars along the friendly side of the minefield when the breach lanes are finished and will engage other targets with mortars and artillery when observed.

Blue has supplemental positions on each flank facing the dismounted avenues of approach along the ridgelines. As these are not a factor in this vignette, they are not displayed.

\section{III.C. Battle Analysis}

The battle is composed of three phases. Phase 1 is the preparation phase, where casualties are caused by indirect fires and long-range direct fire during the breach attempt. Phase 2 is the exchange of long-range direct fire during the passage of the obstacle and the initial movement stage of the assault (ending when troops are dismounted from carriers). Phase 3 is the short-range direct firefight in the close assault.

The most dangerous threat to the Blue position is Red vehicle fire. If all Blue long-range antitank weapons (Dragon and TOW) are destroyed, Red vehicles can remain out of AT4 range and systematically destroy all Blue fighting positions during phase 2 . Destruction of the vehicles before more than one or two can close on the position (phase 3) virtually ensures a Blue victory. If only a few BTR60s get within AT4 range they are quickly destroyed. One or more tanks or a platoon or more of BTR60s allowed to close on the position ensures a Red victory.

The battle position design ensures massed short-range fires on Red dismounted attackers during phase 3. Vehicles must support dismounted Red forces in order to assault the positions unless most Blue have been destroyed by phase 3 .

The broken nature of the terrain is a significant disadvantage to Blue. A partially covered route on the Blue right flank allows some of the Red vehicles to get very close before Blue can engage them, if Blue doesn't kill them in the minefield area.

The Frog minefield produces a target for Blue artillery in a known location. The extensive area covered by breaching teams increases the probability that preplanned fires into the covering smoke will cause casualties. The AP/AT minefield does not cause the 
same lucrative target to blind artillery fires. Even though the breach teams are exposed targets for significantly longer, they are fewer in number, thus providing fewer targets, and cover much less area. The likelihood of a lucky strike is much lower. This also causes a much larger variance in the resulting numbers of casualties. The AT-only case is similar, except the breach is much faster, which further reduces the exposure of Red dismounted soldiers. In the Frog case, a large number of dismounted Red soldiers typically become casualties before even joining into the battle. In the AP/AT and ATonly cases this never occurs.

As the breach force in the Frog minefield takes significant indirect fire casualties, it almost always must be reorganized to complete the breach.

In the AT/AP case, the extended breach time runs the Red artillery through its ammunition stocks and suppression ceases before the attackers begin to traverse the minefield (Red shoots 40 rounds/gun in suppression).

Smoke is a mixed blessing to Red. As Red has many more long-range weapons, he has the ability to dominate the direct fire battle at mid to long ranges (beyond about 500 meters - phase 1 and phase 2). Red-vehicle mounted long-range weapons are all armor protected, thus only vulnerable to a limited number of Blue long-range weapons (TOW and Dragon, as MK19 grenade launchers have limited effects). Smoke reduces the number of Red vehicle weapons that can acquire targets, which is advantageous to Blue, and reduces the number of exposed Red targets (thus allowing concentrating Blue fires) which is also advantageous to Blue. Smoke is necessary, however, to conceal dismounted Red soldiers that would otherwise be vulnerable to long range direct fire (particularly from M60 machineguns and Mk19 grenade launchers) and observed indirect fire.

When Red fails, the assault forces are all in the engagement area and cannot get out without being engaged. All of the Red forces become casualties with the exception of those that have not participated in the assault. In the Frog case, the truck drivers that survived the initial pre-planned Blue artillery remain in defilade with their vehicles and do not become casualties later. The Red mortars are always protected.

When Blue fails, the assault forces physically overrun the battle position and defenders cannot flee without being engaged. All of the Blue forces become casualties, including the Blue mortar crews.

\section{III.D. Preliminary Quantitative Results}

For each scenario, we ran the model ten times. Results shown are averages over the ten runs.

As expected, this is a very difficult defense for Blue. In the three baseline cases (no mines, AT mines only, and mixed AT/AP minefield) Blue loses. Only in the Frog case does Blue win, and it is a high casualty win. 
III.D.1.Duration

Battle durations are shown in table 4.

Table 4. Minefield configuration and results

\begin{tabular}{|l|l|l|}
\multicolumn{1}{c}{ Battle duration } & \multicolumn{1}{c|}{ Winner } \\
\hline No mines & 21 minutes & Red \\
\hline AT & 47 minutes & Red \\
\hline AT/AP & 87 minutes & Red \\
\hline Frogs & 50 minutes & Blue \\
\hline
\end{tabular}

In this particular case, duration is not related to the eventual winner (because Red receives significant advantage from the broken terrain, which in large part nullifies the accuracy and range advantage of Blue's antitank missile systems). Longer duration, however, is directly related to increasing numbers of Red casualties.

Duration for the no mines case is the actual time for the assault from the initial Red battalion march column in defilade until the Blue position is overrun and all Blue personnel are casualties. The additional time in the mine cases reflects time necessary to breach the minefields and maneuver the attacking forces through the lanes.

Battle duration is important, as it is the commitment time for the force. The attacker must complete the battle before being free to continue to a following objective. In a roadblock scenario, such as this, the avenue of approach is not open for following forces until the battle is over. As duration is important in this sense only if the attacker wins, the duration for the Frog case is essentially infinity - the attacker has been destroyed. When this is considered, the delay value of the obstacle, defined as the ratio of battle duration to the length of the battle without mines, is listed in table 5 .

Table 5. Delay multiple

\begin{tabular}{|l|c|c|c|c|}
\hline & No mines & AT only & AT/AP mix & Frogs \\
\hline Obstacle value & 1 & 2.2 & 4.1 & (Red loses) \\
\hline
\end{tabular}

\section{III.D.2.Casualties}

Casualties are shown in Figure 13. This shows that Red has lost in the Frogs case (all personnel except truck drivers are casualties), and that Blue has lost in the remaining cases (all Blue are casualties). These numbers include vehicle crewmembers for Red armored vehicles that were destroyed. 


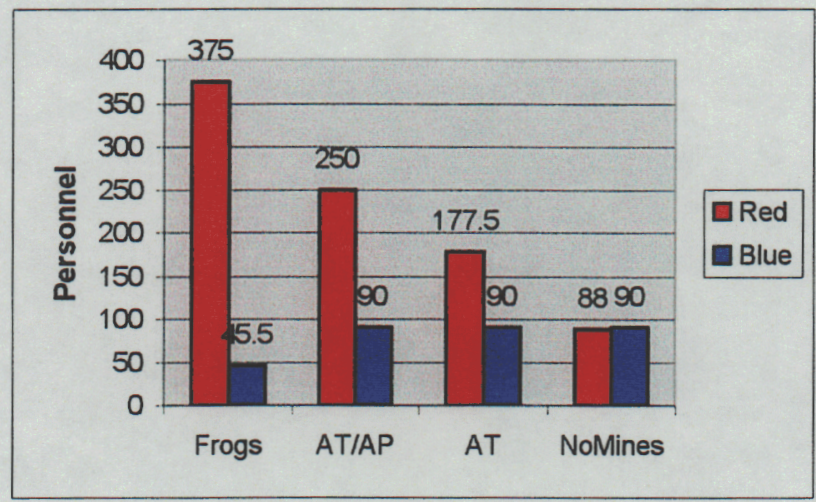

Figure 13. Resulting casualties for Red and Blue

This method of displaying the data is somewhat misleading - it does not allow easy comparisons between cases related to size of each force. Figure 14 shows casualties as a percentage of each force grouped to directly compare cases.

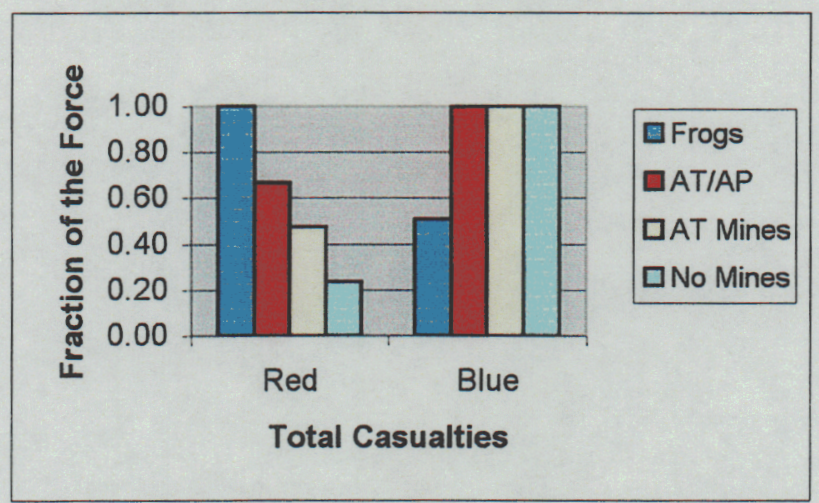

Figure 14. Total casualties as a fraction of the force

This illustrates quite clearly when Red or Blue is the winner. It also allows a fairly clear comparison between outcomes for no mines, AT-only and mixed systems, as for these cases all of the Blue force have become casualties so that the only variation is 
the number of Red casualties. This does not extend to comparison with Frogs, as the Blue casualty number has also changed.

The total casualty number is important beyond the immediate battle, as it is a measure of lost future capability. This is particularly important to the attacker who normally has a series of objectives to take. Table 6 compares the contribution of each of the obstacles as a multiple of Red casualties in row one, and then cross-compares the value of Frogs to each of the others.

Table 6. Red casualty multiple

\begin{tabular}{|c|c|c|c|c|}
\hline & No mines & AT only & AT/AP & Frogs \\
\hline Obstacle value & 1.0 & 2.0 & 2.9 & 4.3 \\
\hline $\begin{array}{c}\text { Comparative } \\
\text { Frog multiple }\end{array}$ & 4.3 & 2.2 & 1.5 & 1.0 \\
\hline
\end{tabular}

In other words, Frogs caused 1.5 times more Red casualties than AT/AP, 2.2 times more than AT only, and 4.3 times more casualties than having no obstacle at all.

\section{III.D.3.Fractional Exchange Ratio}

A better way to compare is to use fractional exchange ratios (FER) as the Measure of Effectiveness (MOE). This value is the fraction of the Red force that has become casualties divided by the fraction of the Blue force that has become casualties. Basically, this is the percent of the Red force removed from battle for every one percent of Blue removed. If the FER is greater than 1.0, Red is losing force faster than Blue and Blue will win (if the battle continues long enough at the same FER). If the FER is less than 1.0 , Blue is losing force faster than Red, and Red will win (also if the battle continues long enough). Fractional exchange ratios are compared in Figure 15.

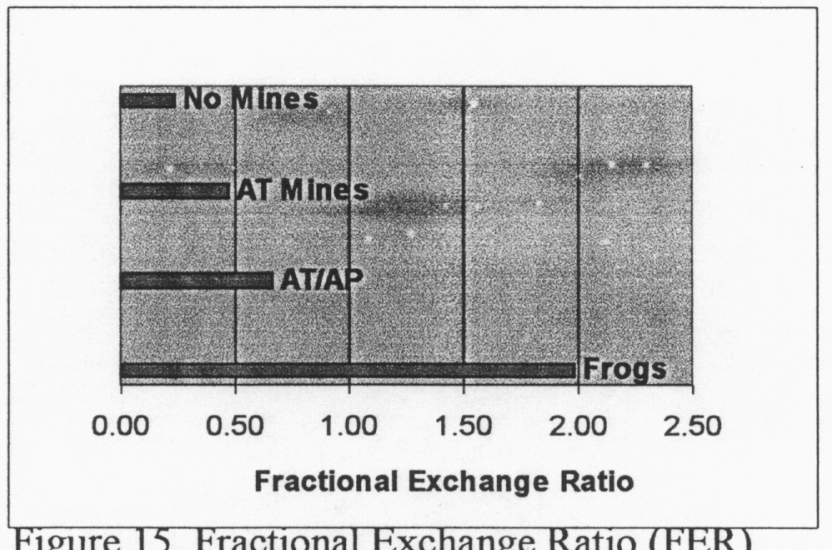

Figure 15. Fractional Exchange Ratio (FER) 
This chart also demonstrates that, except for the Frog case, Blue loses this battle. Adding a simple, AT mine minefield almost doubles the FER. Adding AP mines to the minefield provides almost triple the straight assault FER. The Frogs, however, improve FER by over a factor of eight. Comparing the Frog minefield to the conventional mixed system, the FER is three times better. These comparisons are shown in Table 7.

Table 7. FER obstacle multiple

\begin{tabular}{|c|c|c|c|c|}
\hline & No mines & AT only & AT/AP & Frogs \\
\hline Obstacle value & 1.0 & 2.0 & 2.9 & 8.6 \\
\hline $\begin{array}{c}\text { Comparative } \\
\text { Frog multiple }\end{array}$ & 8.6 & 4.3 & $3.0^{\circ}$ & 1.0 \\
\hline
\end{tabular}

\section{III.D.4. Breaching Costs}

The attacking Red force must allocate some of its combat power to dealing with the minefield (zero in the no mine case). This force is exposed and can take casualties, a "cost" imposed by having to breach that reduces the force available for later employment. Table 8 lists these breaching costs for the various obstacle cases.

Table 8. Breaching costs

\begin{tabular}{|l|c|c|c|c|c|c|c|}
\hline & $\begin{array}{c}\text { Breach } \\
\text { Time } \\
\text { (minutes) }\end{array}$ & $\begin{array}{c}\text { Initial } \\
\text { Breach } \\
\text { Personnel }\end{array}$ & $\begin{array}{c}\text { Final } \\
\text { Breach } \\
\text { Personnel }\end{array}$ & $\begin{array}{c}\text { Breach } \\
\text { Man-hours }\end{array}$ & $\begin{array}{c}\text { Breach } \\
\text { Casualties }\end{array}$ & $\begin{array}{c}\text { Breach } \\
\text { Casualty } \\
\text { rate }\end{array}$ & $\begin{array}{c}\text { Breach } \\
\text { Casualty } \\
\%\end{array}$ \\
\hline No Mines & 0 & 0 & 0 & 0 & 0 & 0 & 0 \\
\hline AT & 21 & 54 & 72 & 25 & 23 & 1.1 & 32 \\
\hline AT/AP & 74 & 54 & 108 & 133 & 60 & 0.8 & 56 \\
\hline Frogs & 28 & 162 & 216 & 101 & 178 & 6.4 & 82 \\
\hline
\end{tabular}

The breach time is self-explanatory. Initial breach personnel are the number initially assigned to the breach mission. Final breach personnel were those necessary to complete the mission after casualties. This indicates the reorganization requirements and some of the command and control stresses. Breach casualties are those members of the squads attempting to breach that became casualties during the attempt - including new squads added to the breach force during the battle. Breach casualty rate is a measure of intensity - it is the average number of casualties occurring per minute during the breach. It can be linked to psychological stress on the individual soldier as well as his leader.

Table 9 displays the force that an attacking enemy must provide to accomplish the breach. The first row is in terms related to a simple AT minefield (i.e., how much larger the breach force must be for an AT/AP or Frog minefield). The second row compares the force necessary to breach the Frog minefield with the other obstacle types. 
Table 9. Required breaching force multiples

\begin{tabular}{|c|c|c|c|c|}
\hline & No mines & AT & AT/AP & Frogs \\
\hline Obstacle value & 0 & 1.0 & 1.5 & 3.0 \\
\hline $\begin{array}{c}\text { Comparative } \\
\text { Frog multiple }\end{array}$ & 0 & 3.0 & 2.0 & 1.0 \\
\hline
\end{tabular}

In terms of Red forces required to deal with the obstacle, Frogs require three times as many as a simple AT minefield, and twice as many as required by the current mixed minefield. Table 10 shows similar data, but for casualties during the breach. This is a permanent reduction in the attacking force and has significance for later battles.

Table 10. Breaching force casualties multiples

\begin{tabular}{|c|c|c|c|c|}
\hline & No mines & AT & AT/AP & Frogs \\
\hline $\begin{array}{c}\text { Breaching } \\
\text { casualty value }\end{array}$ & 0 & 1.0 & 2.6 & 7.7 \\
\hline $\begin{array}{c}\text { Comparative } \\
\text { Frog multiple }\end{array}$ & 0 & 7.7 & 3.0 & 1.0 \\
\hline
\end{tabular}

The Frogs cause almost eight times the casualties as a simple AT minefield, and three times the number caused by today's mixed minefield.

A final comparison is the reduction in dismounted soldiers available to conduct the final assault on the battle position. The following set of figures shows the percentage of the force used up in the breach and that still available (in red) to conduct the final assault. In this battalion-size attack, the attacker used up almost one-half of his assault force simply getting through the Frog obstacle. 

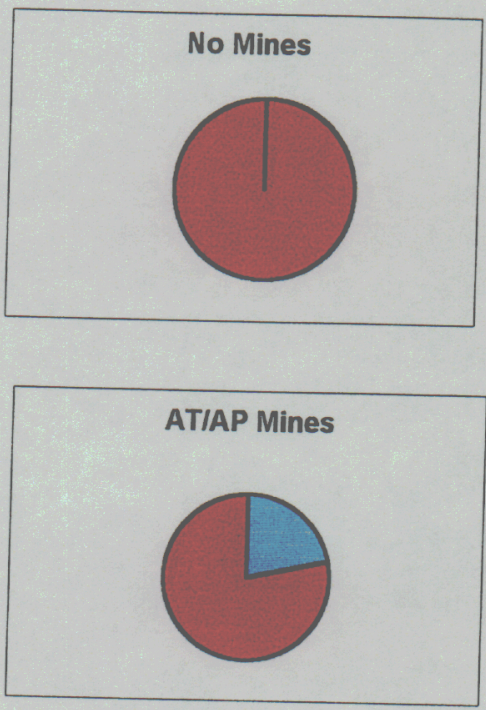

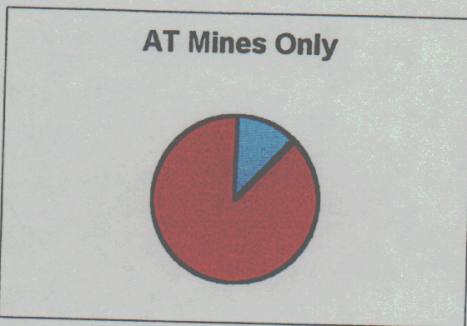

Self-Healing Minefield

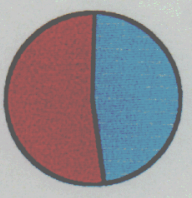

Figure 16. Forces used in breach (blue) and forces remaining (red)

\section{III.D.5.Summary}

In order to establish the comparative value of Frogs versus the AT minefield or the mixed AT/AP minefield, it is necessary to establish a frame of reference. If the value to the current battle is important, the fractional exchange ratio, the required breach force, and the breach force casualties are the critical values to examine. All three are important to winning the battle - the first as an exact measure of how well the battle is going, and the remaining two as measures of how many forces must be devoted to the breach during the battle. If a larger frame of reference is chosen, the impact of this battle on the entire operation becomes critical - not only winning or losing, but also the drain on enemy resources and timing. Battle time and total casualties become important criteria. These values are displayed in Table 11. All values in Table 11 have been, so that FER, time, and total Red casualties are shown as 1 for the no-mines case, while breach force and breach casualties (both zero for a scenario with no mines) are shown as 1 for the AT mines case. The other numbers in the table are multiples of these. 
Table 11. Battle times and casualties

\begin{tabular}{|c|c|c|c|c|c|}
\hline & FER & Breach Force & $\begin{array}{c}\text { Breach } \\
\text { Casualties }\end{array}$ & Time & $\begin{array}{c}\text { Total Red } \\
\text { Casualties }\end{array}$ \\
\hline No mines & 1.0 & 0.0 & 0.0 & 1.0 & 1.0 \\
\hline AT & 2.0 & 1.0 & 1.0 & 2.2 & 2.0 \\
\hline AT/AP & 2.9 & 1.5 & 2.6 & 4.1 & 2.9 \\
\hline Frogs & 8.6 & 3.0 & 7.7 & 2.4 & 4.3 \\
\hline
\end{tabular}




\section{Appendix A}

\section{System Characterization Process}

1. Establish Minefield:

_ Position all mines in X, Y coordinate system: (use Volcano canister dispensing angles and velocities for each mine. Launch each canister from a progressive launch point spaced appropriately. Apply a gaussian distributed random error to both angle and velocity for each mine at launch. Establish polar orientation (randomly) for each mine upon landing.

- Build table for each mine identifying those other mines within its area of interest. Determine range and angle to each friend. Place each friend in one of the mine's sectors.

_ Establish baseline signal strength within each sector for each mine.

2. Breach:

- Remove mines found within two and $1 / 2$ meters each side of the breach lane centerline.

\section{Repair Minefield:}

- Each mine checks for presence of original mines within area of interest.

- If any mine is missing, the mine checks the signal strength in that quadrant.

- If signal strength has decreased less than a defined threshold, the mine moves in the direction of the sector (modified by random errors in range and azimuth).

- If any mine has moved, repeat this process for the other mines.

4. Determine mine density remaining across frontage. Count remaining mines in each 5-meter wide strip across the width of the minefield.

\section{Repeat steps 2 through 4 until breach is successful (no mines move to close lane).}

\section{Generate statistically significant results}

Store data (mine density after each breach \& heal cycle, number of cycles until successful breach)

_ Repeat entire process sufficient times to have statistically meaningful densities. 